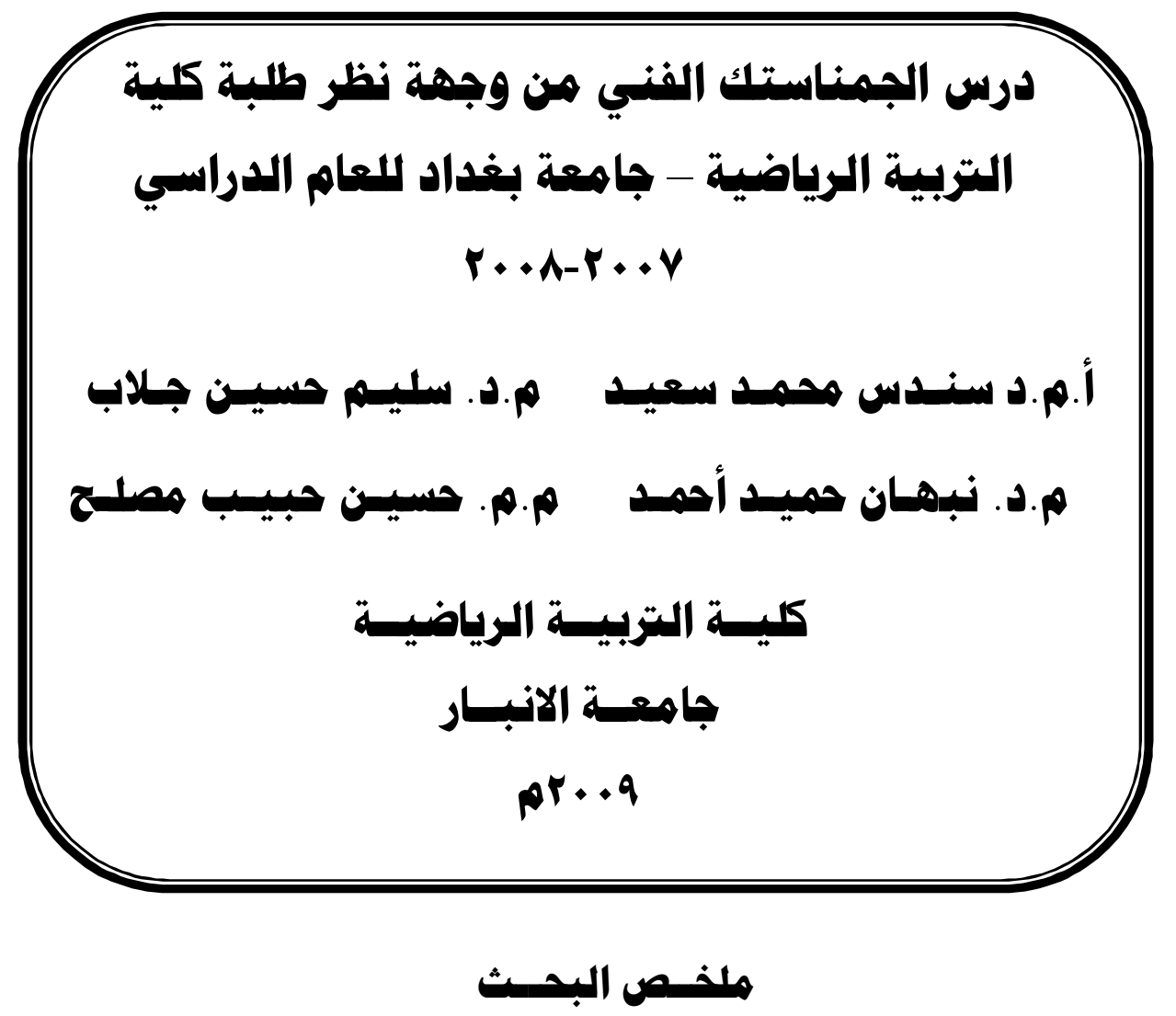

درس الجمناسـتك مـن وجهـة نظر طلبـة كليـة التربيـة الرياضـية - جامعـة بغـداد للعـام الدراسـي

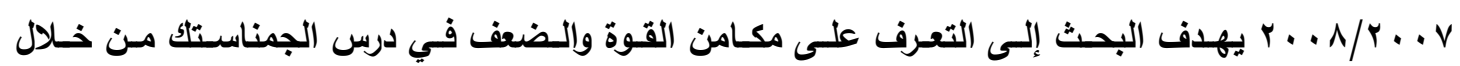
استجواب المبحوثين على ذلك وأقترض البحث الأكثر الأجهزة والحركات المطلوية لكل جهاز يؤدي إلى إرباك الطالب وعدم تعلمه الحركة بثكل جيا ومتقن وقثلة الوقت المخصص لارس الجمناستك وتم أجراء البحث على الاجلى

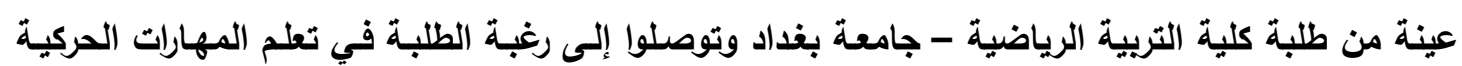
الخاصة بلرس الجمناستك بعد الحصص وعرض الحركة من قبل المدرس تلقى قبولا إضافة إلى استخدام صور تحليلية وتوضيحية وأوصـوا بضرورة بنـاء قاعدة ذات مواصفات خاصـة وضـرورة تـوفير الأفلام السينمائية وزيادة عدد التدريسيين المختصين بالجمناستك الفني .

\title{
Lesson of gymnastic from the point of view the college
} of sport-education-university of Baghdad

For the year $2007-2008$

The research aim to learn (know)aboutch the place of strong and weak in the lesson of gymnastics through out the question ofabout that -the assumptionof the research is increase the equipment and motion which demands eah equipment leads to onfuse the student and prevent him motion in good manner and not enough time for the lesson of gymnastics the research performed in the college of sport-education .university of Baghdad and reach to desire the students in learning agood motions concerned with the lesson of gymnastics after the lessons and show the motion by the teacher received satisfactions in addition to the use of analytical, explanatory and demanded the 
necessity to provide dramatic films and increase the nembers of teachers who spicailized in gymnastes art

\section{البـاب الأول}

التتهريف بالبشث

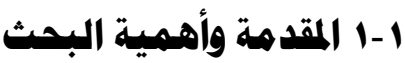

مع بلا الخليقة عرف الإنسان الألعاب الرياضية بوجه عام والجمباز بوجه خاص فالإنسان الأول لم الم

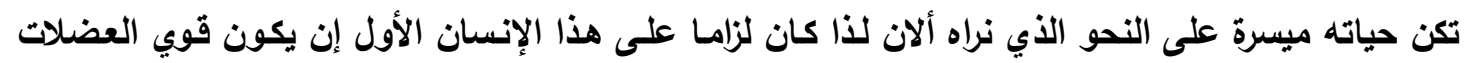
سريعا في جريه معتمدا في بقاءه على مدى ما يبذله من مجهود جسمي كبيز . الجمباز نشاط من أنشطة

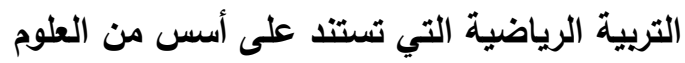
الطبيعية والإنسانية،فالجمباز يأخذ من علوم الرياضيات والميكانيكا والتشريح ووظائف الأعضاء وغيرها من العلوم الطبيعية والإنسانية يأخذ الجمباز من علم النفس التربوي وطرق التدريس وغيرها ،فالجمباز يمكن

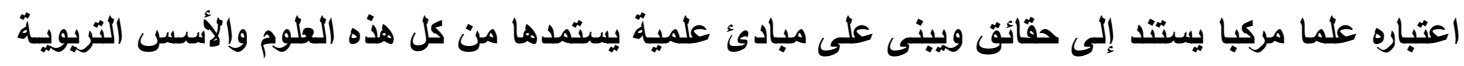
والنفسية.إن التعرف على واقع اللعبة وكثف أسباب معوقاتها بأسلوب علمي بناء يتيح لمدرسي ومدربي هذه هذه

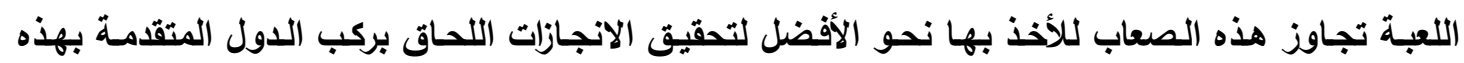


تكمن مشكلة البحث في تلني مستوى أداء الطلبة في الاروس العملية ولأجل الوقوف على الأخطاء

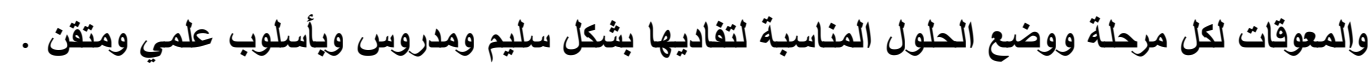
ارتأى الباحثون البحث بهذا الموضوع والذي يخص درس الجمناستك الفني من وجهة نظر طلبة كلية التربية الرياضية - جامعة بغداد ويمكن اعتباره دليل عمل سليم للمرحلة المقبلة وللذين يقودون هذه اللعبة ولئ وللاستفادة منها في السنوات المقبلة .

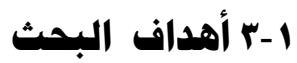
يرهف البحث إلى :-

1. التعرف على مكامن القوة والضعف في درس الجمناستك من خلال استجواب المبحوثين على ذلك

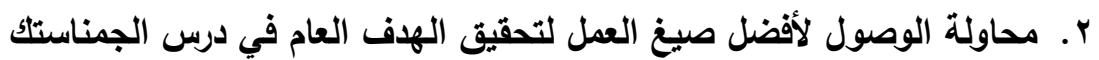

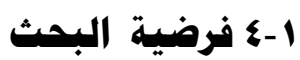

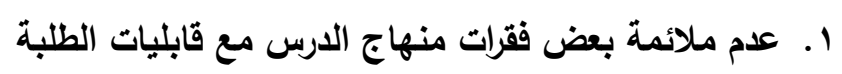

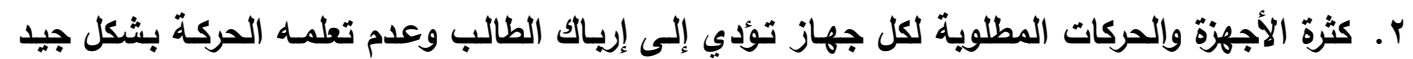
ومتقن r. قلة الوقت المخصص لدرس الجمناستك

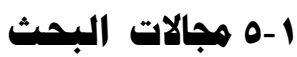

1-0-1 المجال البشري : - - طلبة المرحلتين الأولى والثانية .

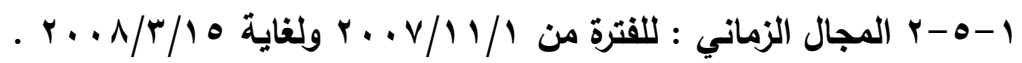

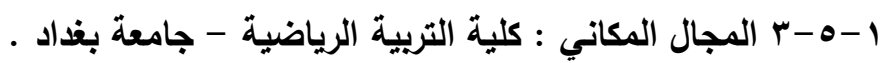




\section{البـاب الثانسي}

r r الدراسات النظرية

r-ا درس البمن:استك الفني

ان لارس الجمناستك إمكانيات كثيرة ومختلفة والهدف منه تحقيق اكبر عدد ممكن من الحركات بأقل وقتت

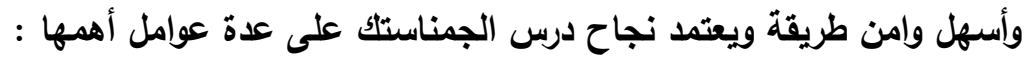

> ق قارة الطالب على تفهم الحركة

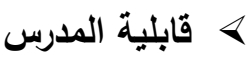

وان الإلمام الكافي لمدرسي الجمناستك للنواحي المهمة في تطلم الطلاب الحركات الجمناستيكية والوصول

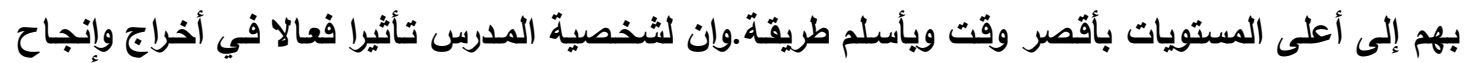

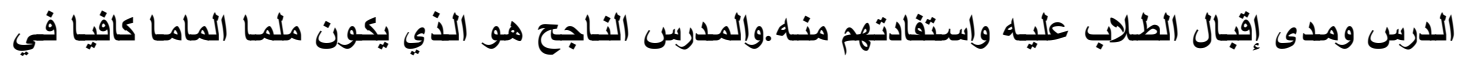

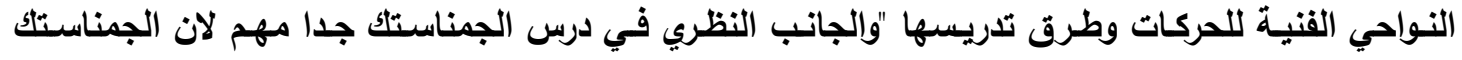

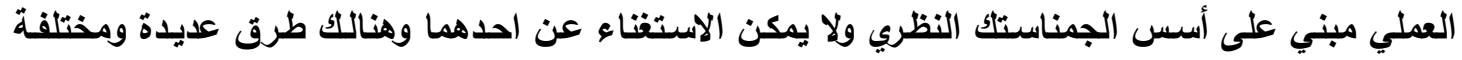

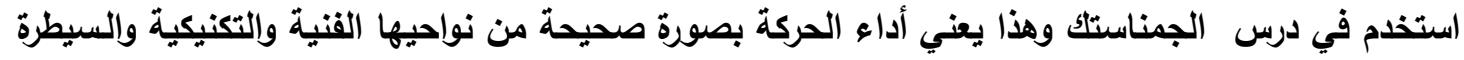

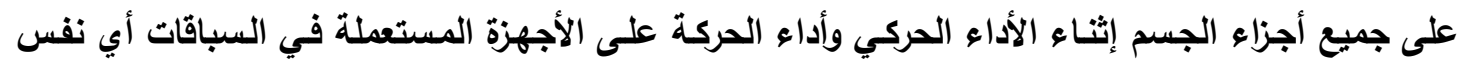

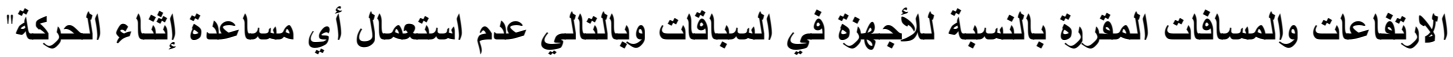

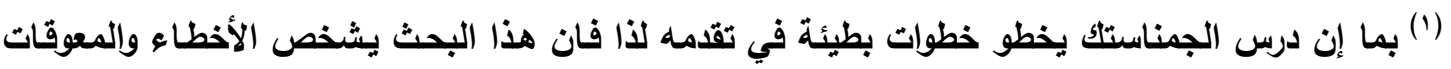
ويضع الحلول المناسبة لتفاديها بشكل سليم ومدروس وهدفنا هو مساهتتا في المجال لرفع الحركة الرياضية

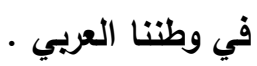

\section{r-1-1 أهمية درس الجمناستك}

يعتبر الجمناستك ناحية من نواحي النشاط البدني ويتميز" بتأثيره الثامل على المجاميع الفصلية

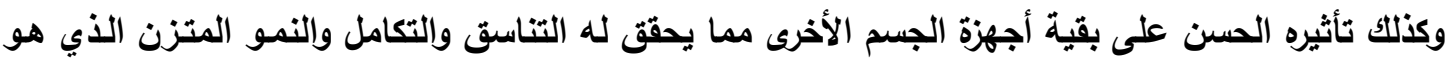

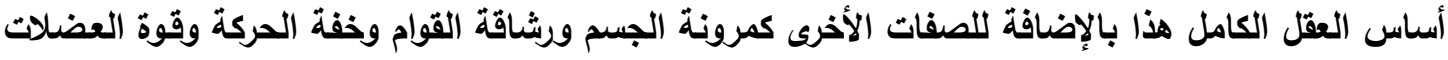

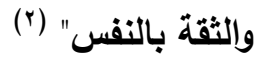

\section{r-r-r أهمية النواحي النظرية في الجمناستك}

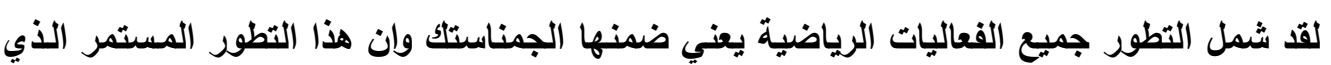

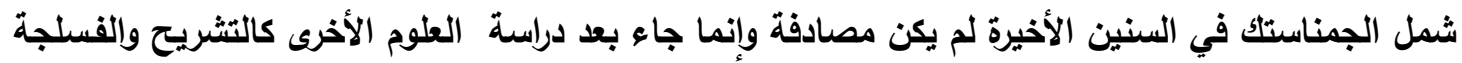

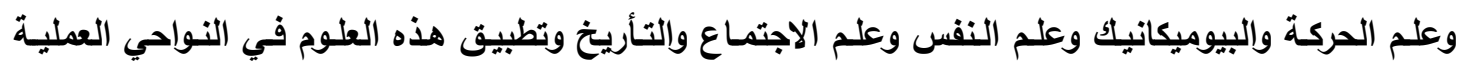

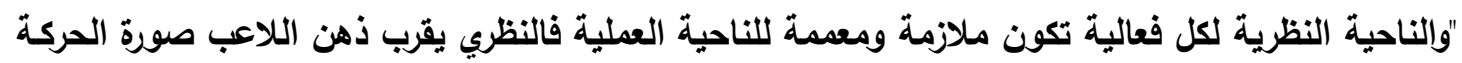

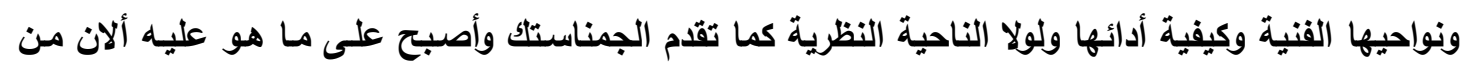

(1) يوركن لايرش :عبد السلام عبد لرزاق، صائب العبيدي ؛ الاسس النظرية في الجمناستك ، طץ :( العراق ، مطبعة جامعة 
صعوية في الأداء والتطور الفني لذا فالناحية النظريـة ضرورية في تدريساتنا العملية وعلى مدرس التربية

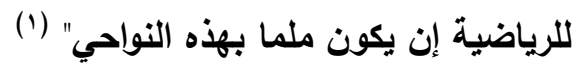

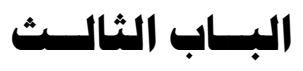

r- منهه البمث وإجراءاته الميدانية

1-r منهج البحث

استخدم الباحثون المنهج المسحي

r-r عينة البصث

تبلغ عينة البحث ( 1 (1) طالبا من طلبة المرحلة الأولى والثانية من كلية التربية الرياضية-جامعة

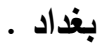

r-r ادوات البحث

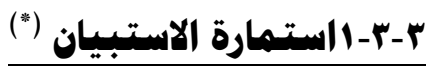

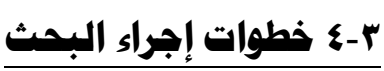

ب- ب- التجربة الاستطلاعية

قام الباحثون بأجراء التجربة الاستطلاعية كباية لعملهم ، وذلك للحصول على نتائج دقيقة يستفاد منها عند إجراء التجرية الرئيسية والتعرف على السلبيات والمعوقات التي ترافق تطبيق تجرية البحث ـ ـ بتاريخ

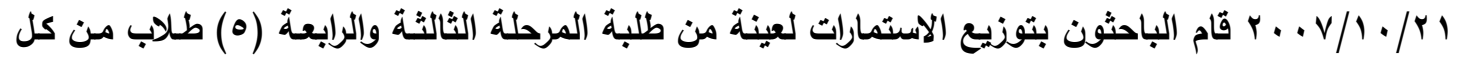
مرحلة ، هناك أسس علمية يجب وضعها في الحسبان عند إجراء الاختبار وهي الثبات والصدق والموضوعية

r-צ-1 -ا ثبات الاختبار

ولغرض الحصول على ثبات الاستمارة تم استخدام طريقة إعادة الاختبار وذلك من خلال توزيع الاستمارة (ه) طالبان من طلاب المرحلة الثالثة والرابعة والذين يمثلون ( كلية التربية الرياضية - جامعة بغداد) كاختبار

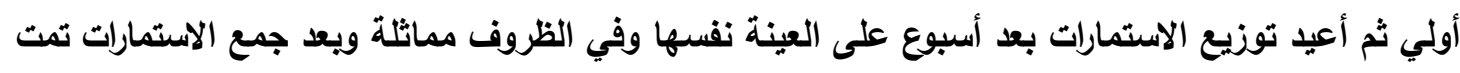

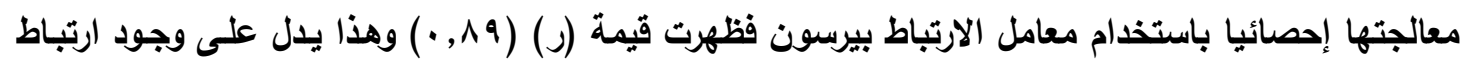

عال ومن ثم وجود معامل ثبات الاستمارة .

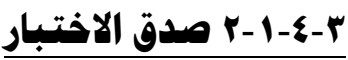

فضلا عن أجراء العديد من الدراسات في المجال الرياضي لا يتسع المجال استعراضهها ـ وزيادة في

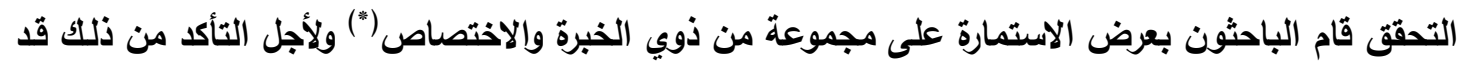

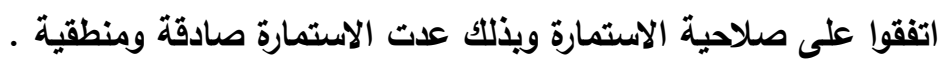

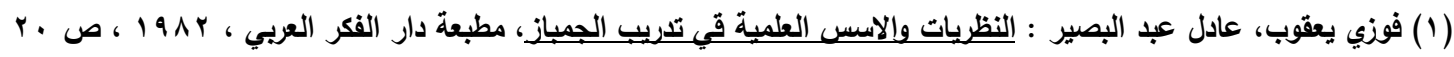

* انظر ملحق رقم (1)

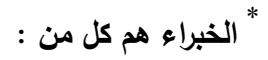

\begin{tabular}{|c|c|c|}
\hline جامعة بغداد & كلية التربية الرياضية & هدى ابراهيم ارزوقي \\
\hline جامعة تكريت & كلية التربية الرياضية & فاتن محمد رشيد \\
\hline جامعة البصرة & كلية التربية الرياضية & لمياء الديوان \\
\hline الجامعة المستتصر & كلية المعلمين الأساس & ايمان حمد شهاب \\
\hline
\end{tabular}




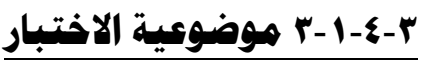

أن الاستمارة تتميز بوضوح وأسئلتها وإجاباتها محددة ، مما يفستح المجال أمام أفراد العينة من فهم

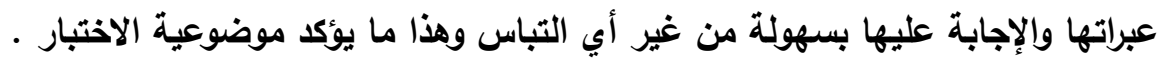


§- عرض ومناقشة وتليل النتائج

§-1 أعرض وتصليل النتائج

س 1 ها هو رأيك برهمن حصة درس البمناستك

\begin{tabular}{|c|c|c|}
\hline$\%$ & ك & الإجابة \\
\hline$\%$ \% & $|r|$ & كافي \\
\hline$\%$ \%r & 7. & غير كافي \\
\hline$\% 1 \ldots$ & $\mid 11$ & المجموع \\
\hline
\end{tabular}

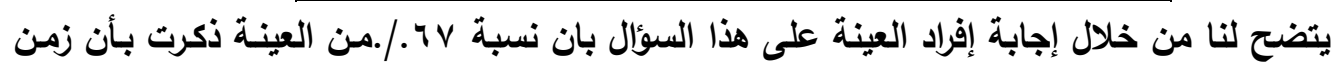

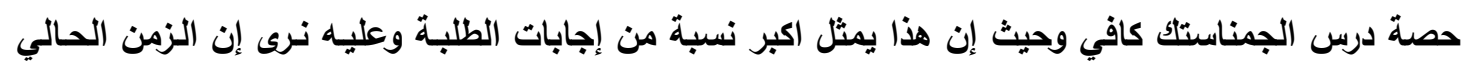

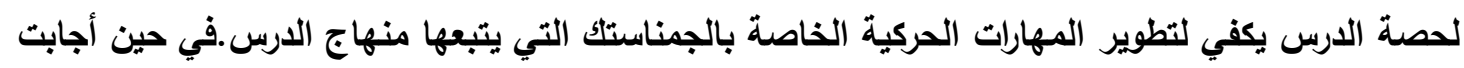

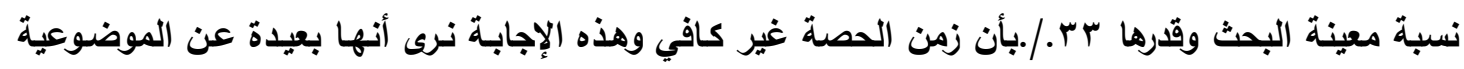

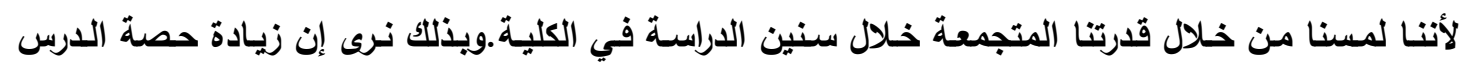

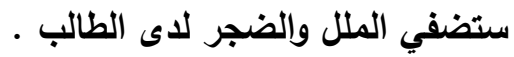
سمr. ها هو الوقت المناسب لدرس الجمناستك

\begin{tabular}{|c|c|c|}
\hline$\%$ & ك & الإجابة \\
\hline$\% \wedge 4$ & 107 & $\Lambda_{6} r$. \\
\hline \multirow{2}{*}{$\% 1 \varepsilon$} & ro & $1.6 \%$ \\
\hline & & IT,T. \\
\hline$\% 1 \ldots$ & 111 & المجموع \\
\hline
\end{tabular}

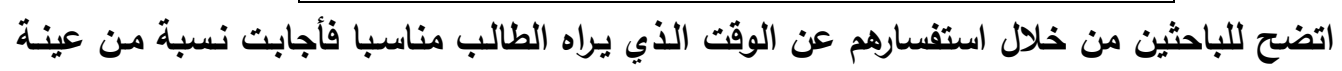

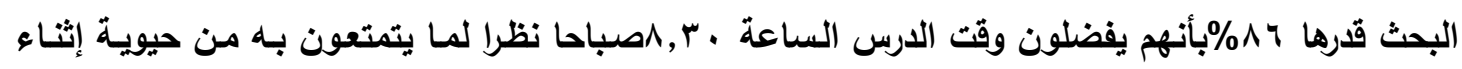

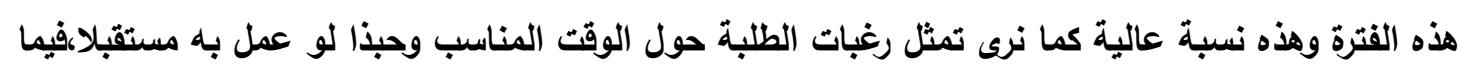

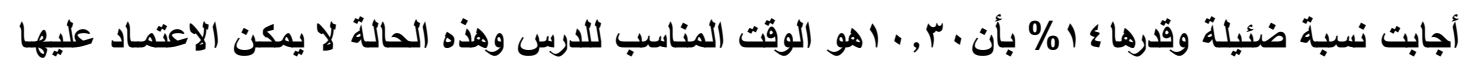

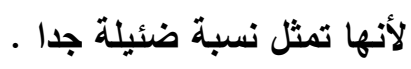

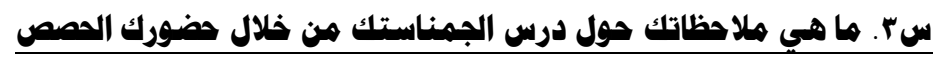

\begin{tabular}{|c|c|c|}
\hline$\%$ & S & الاجابة \\
\hline$\% q \varepsilon$ & iv. & الرغبة في التعلم \\
\hline$\% 4$ & 11 & الملل \\
\hline$\% 1 \ldots$ & 111 & المجموع \\
\hline
\end{tabular}

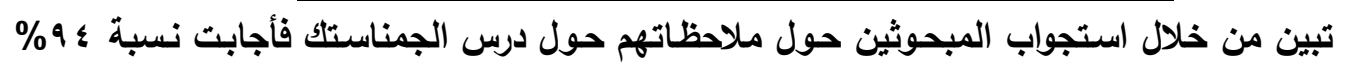

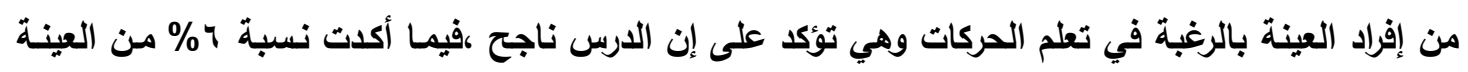


على الثعور بالملل.وطبيعيا يعزى سبب شعورهم بالملل إلى أسباب متعددة ويظهر لنا الجدول التالي أهم

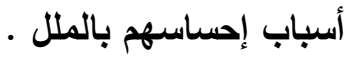
سـ ع. هل تعتقد إن حالة الطالب الذي لا يرغب في دخول درس الجمناستك يرجع للأسباب التالية

\begin{tabular}{|c|c|c|}
\hline$\%$ & ك & الإجابة \\
\hline$\% 17$ & rq & عدم وجود محفزات \\
\hline$\% \wedge$ & 10 & عدم تثمين الجهود \\
\hline$\% r q$ & v. & خوفا من الاجابات الرياضية \\
\hline$\% 0$ & $\wedge$ & عامل الخجل \\
\hline$\%$ \% & $\varepsilon \varepsilon$ & عدم امتلاك الصفات الجيدة للاعبي الجمناستك \\
\hline$\% r$ & 7 & عوامل اخرى \\
\hline$\% 0$ & 9 & مُم تجب \\
\hline$\% 1 \ldots$ & $\mid \wedge 1$ & 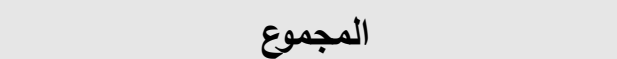 \\
\hline
\end{tabular}

اتضح للباحثين من خلال هذا الجدول بأن عدم رغبة الطالب في دخول درس الجمناستك يعود إلى

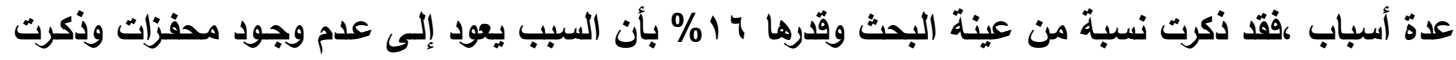

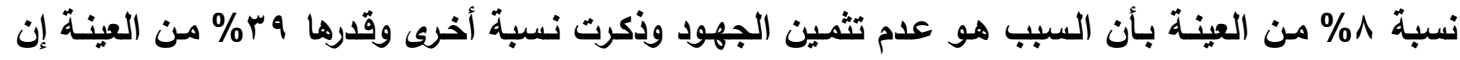

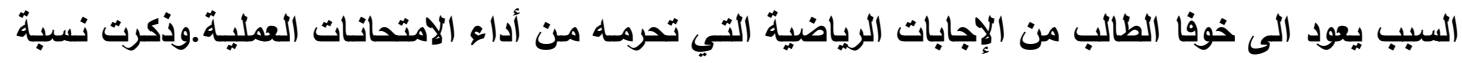

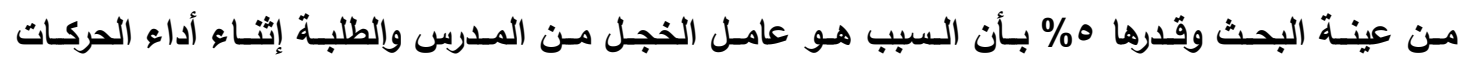

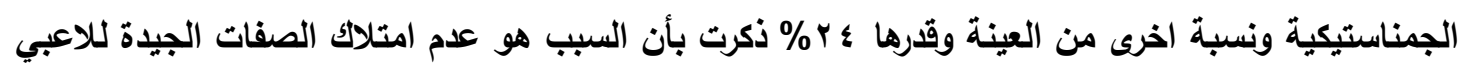
الجمناستك وهذا يجعل اللاعبين غير راغبين في حضور الدرس لذا يؤكد الباحثون على ضرورة تثمين جهود

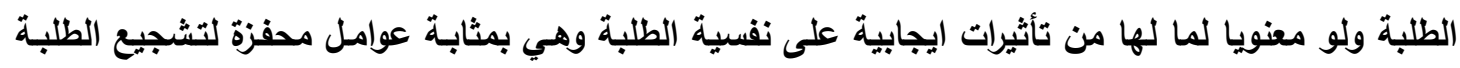

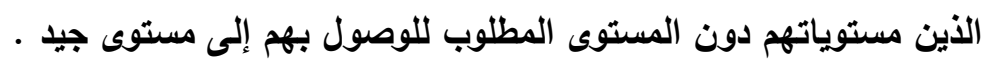

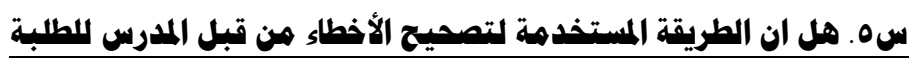

\begin{tabular}{|c|c|c|}
\hline$\%$ & ك & الإجابة \\
\hline$\% 90$ & IVY & تلقى قبولا \\
\hline$\% r$ & $\varepsilon$ & تلقى رفضا \\
\hline$\% r$ & 0 & لم تجب \\
\hline$\% 1 \ldots$ & $|\wedge|$ & المجموع \\
\hline
\end{tabular}

توصل البـاحثون مـن خـلال استجوابهم مجموعـة المبحوثين حول الطريقة المستخدمة لتصحيح

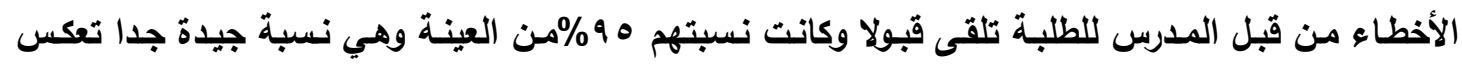

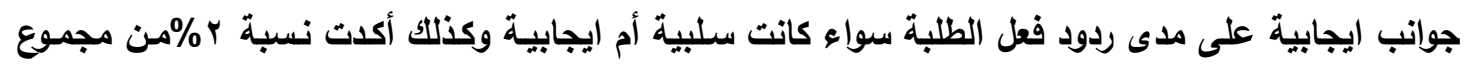
العينة تلقى رفضا وهي نسبة ممكن إن يكسبها المدرس والتي ترجع إلى الأسـاليب التربويـة التي يعتبرها المدرس جادة في خلق الجو التريوي لخلق قادة المستقبل الناجحين س1. هل تعتقد ان هشاركة المدرس هـو الطلاب بأداء الحركات إثناء درس الجمناستك يثير الحماس والمنافسة 


\begin{tabular}{|c|c|c|}
\hline النسبة \% & ك & الإجابة \\
\hline$\% 94$ & ivo & نعم \\
\hline$\% r$ & $r$ & كلا \\
\hline$\% r$ & $r$ & لم تجب \\
\hline$\% 1 \ldots$ & $|\wedge|$ & المجموع \\
\hline
\end{tabular}

استتتج الباحثون من خلال استفسارهم حول مشاركة المدرس مـع الطلبة بأداء الحركات وهل يثير

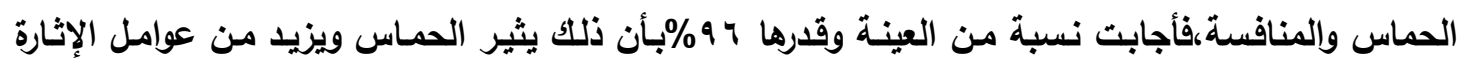
والتثويق لدى الطلبة وهي نسبة عالية تعكس جوانب جيدة يمكن إن يتبعها المدرس في أصفاء جو المرح والسرور في الدرس وذكرت نسبة ب\%من العينة بالنفي وهي نسبة ضئيلة جدا لذا وجب على المدرس مشاركة

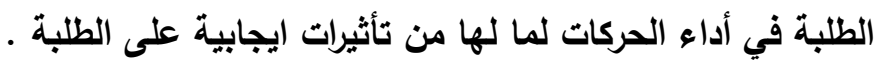

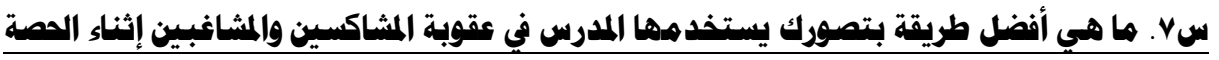

\begin{tabular}{|c|c|c|}
\hline النسبة & 5 & الإجابة \\
\hline$\% 10$ & $r v$ & عقاب بدني \\
\hline$\% r$ & $\varepsilon$ & عقاب نفسي \\
\hline$\% \wedge$ & 10 & ترك الحصة \\
\hline \% v० & 1 & التوجيه الصحيح \\
\hline$\% 1 \ldots$ & $|\wedge|$ & المجموع \\
\hline
\end{tabular}

توصل الباحثون من خـلال استفسارهم حول افضل طريقة يستخدمها المدرس في معاقبة الطالب

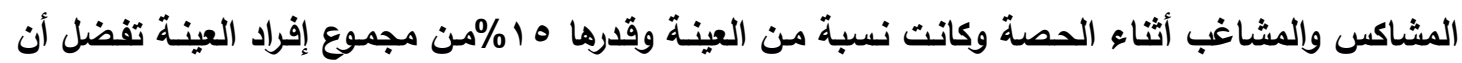

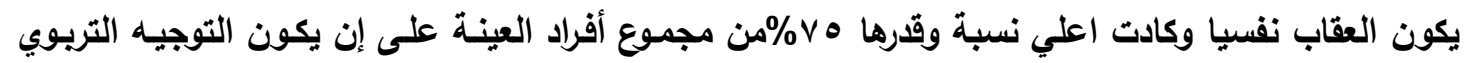

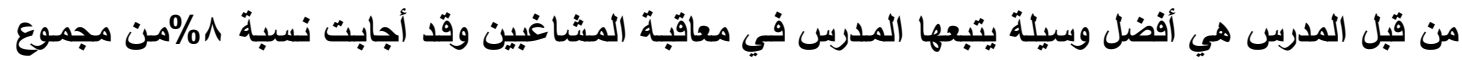
العينة على أنها تفضل ترك الحصة هنا يفضل الباحثون على أن يكون العقاب بلنيا مقرونا بالتوجيه الصحيح

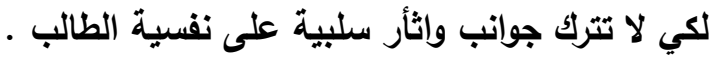

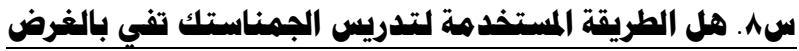

\begin{tabular}{|c|c|c|}
\hline$\%$ & ك5 & الإجابة \\
\hline$\% \vee 7$ & $1 \mathrm{HA}$ & نعم \\
\hline$\% r \leq$ & $\varepsilon r$ & كلا \\
\hline$\% 1 \ldots$ & 111 & المجموع \\
\hline
\end{tabular}

اتضح للباحثين إن الطريقـة المستخدمة لتدريس مـادة الجمناستك تفـي بـالغرض مـن خـلال إجابـة

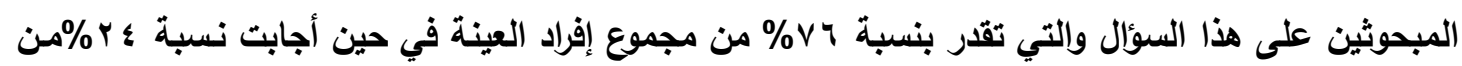
العينة على أنها لا تفي بالغرض وهنا يجب أن يشخص المدرس مكامن الخطأ والضعف لكي تكون الطريقة 
المستخدمة والمتبعة تفي بالغرض الذي يسموا أليه مدرسي الجمناستك لأجل النهوض باللعبة إلى المستوى الأمثل والنموذجي لدرس الجمناستك .

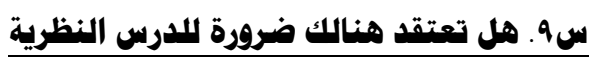

\begin{tabular}{|c|c|c|}
\hline النسبة \% & كs & الإجابة \\
\hline$\% 91$ & 170 & نعم \\
\hline$\% 9$ & 17 & كلا \\
\hline$\% 1 \ldots$ & $|\wedge|$ & المجموع \\
\hline
\end{tabular}

توصل الباحثون من خلال استجواب المبحوثين عن مدى ضرورة وأهمية الدروس النظريـة فأجابت

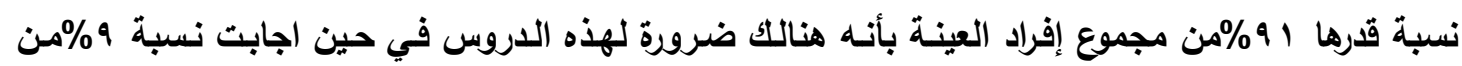
مجموع إفراد العينة بأنه ليس هنالك ضرورة للارس النظرية وقد يعزى السبب إلى عاملين أولههـا عدم وجود

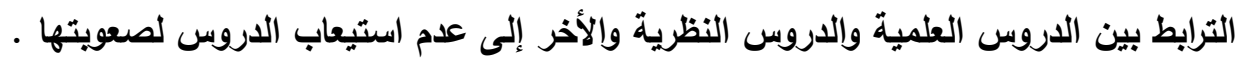

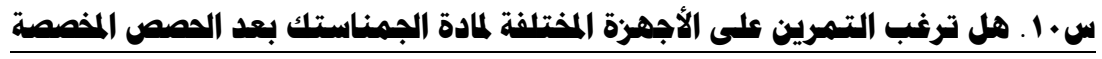

\begin{tabular}{|c|c|c|}
\hline النسبة \% & ك5 & الإجابة \\
\hline$\% \vee \vee$ & $1 \leq$. & نعم \\
\hline$\%$ \%r & $\leqslant 1$ & كلا \\
\hline$\% 1 \ldots$ & 111 & المجموع \\
\hline
\end{tabular}

استنتج الباحثون من خلال استجوابهم لعينة البحث حول مدى رغبة الطلبة في التمرين على الأجهزة

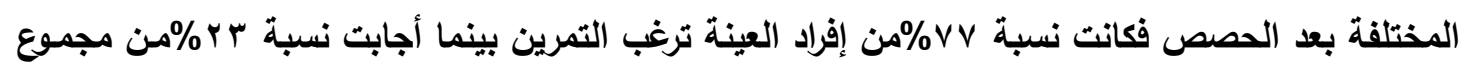
العينة بأنها لا ترغب التمرين بعد الحصص وطبعا هذا يرجع إلى أسباب عدة وسنتعرف فيما يلي عن أهم

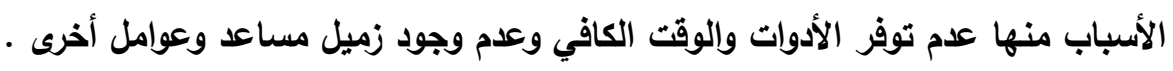

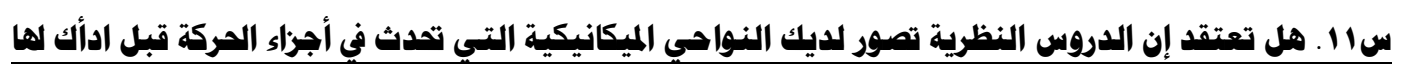

\begin{tabular}{|c|c|c|}
\hline النسبة \% & ك5 & الإجابة \\
\hline$\% \wedge$. & $1 \leqslant \varepsilon$ & نعم \\
\hline$\%$ r. & rv & كلا \\
\hline$\% 1 \ldots$ & $1 \wedge 1$ & المجموع \\
\hline
\end{tabular}

توصل الباحثون من خلال توجيه استفسارهم حول الدرس النظرية وهل تصور النواحي الميكانيكية للحركة قبل الادعاء وقد أجابت نسبة ـــمن مجموع الطلبة بأنها تصور بشكل واضـح النواحي الميكانيكية

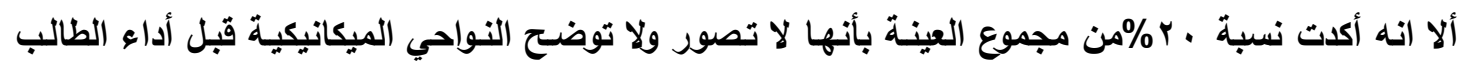

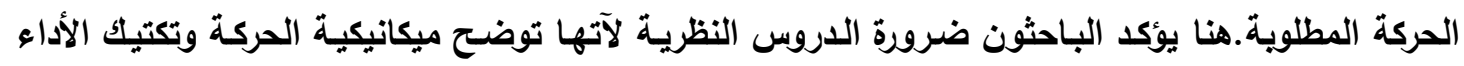

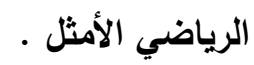




\begin{tabular}{|c|c|c|}
\hline النسبة\%\% & ك & الإجابة \\
\hline$\% \vee 4$ & IrV & عرضها من قبل المدرس عدة مرات \\
\hline$\% 10$ & $r \wedge$ & استخدام صور تحليلية وتوضيحية للحركة \\
\hline$\% \vee$ & ir & عرضها من قبل زميل يجيد عرض الحركة \\
\hline$\% r$ & $\varepsilon$ & لم تجب \\
\hline$\% 1 \ldots$ & 111 & 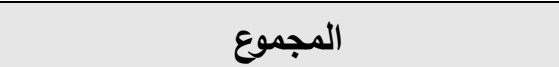 \\
\hline
\end{tabular}

استتنج الباحثون حول استفسارهم عن أي الطرق التي يفضلها الطالب عند تعلمه حركة جمناستيكية

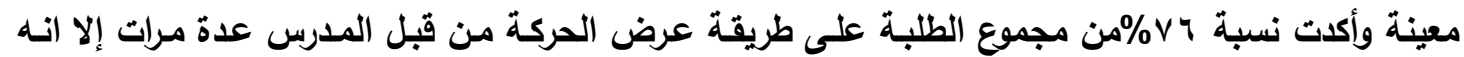

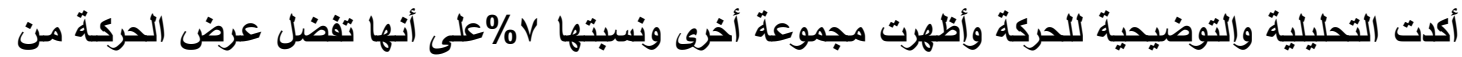
قبل زميل يجيد عرض الحركة وهنا توصل الباحثون إلى إن أفضل طريقة يرغبها الطالب عند تعلم حركة هي عرضها من قبل المدر

\section{سזا . هل تعتقد إن درس الجمناستك يبين شخصية الطالب هن الناحية البدنية والتربوية}

\begin{tabular}{|c|c|c|}
\hline النسية \% & ك5 & الإجابة \\
\hline$\% \wedge \diamond$ & lor & نعم \\
\hline$\% 1 \leq$ & Y & كلا \\
\hline$\% 1$ & $r$ & لم تجب \\
\hline$\% 1 \ldots$ & $|\wedge|$ & المجموع \\
\hline
\end{tabular}

من خلال هذا الجدول يتضح ان نسبة ه^\%من مجموع الطلبة تؤكد على ان درس الجمناستك يبين شخصية الطالب بلنيا وتريويا وهي نسبة تعكس جوانب ايجابية عن مستوى نجاح المدرس واللارس بنفس

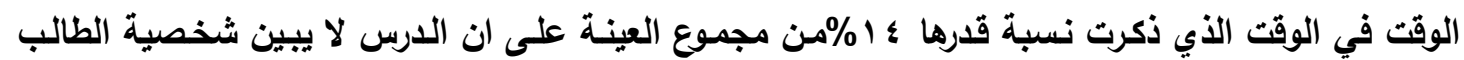

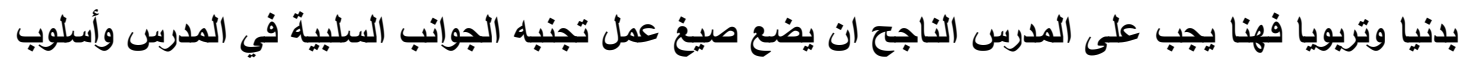

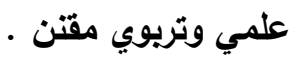
سـا ـ هل هنالك هقترحات تود ذكرها تساءد على تطوير درس الجمناستك في الكلية

\begin{tabular}{|c|c|c|}
\hline النسبة \% & ك & الإجابة \\
\hline$\%$ & 70 & نعم \\
\hline \% ฯ & 117 & كلا \\
\hline$\% 1 \ldots$ & 111 & المجموع \\
\hline
\end{tabular}

توصلنا من خلال هذا السؤال إلى المقترحات التي تسهم في تطوير درس الجمناستك في الكلية وقد أجابت نسبة قدرها ء \\%من مجموع إفراد العينة بأنه ليس لها مقترحات تود ذكرها.ويطمح الباحثّون إن تكون هذه طريق التحليل العلمي الصحيح للبناء ووضع المقترحات إمسام المسئولين إلافاضل لعلها تساهم في رفع وتائر بطاقة اكبر نحو الانجاز الأفضل . 
س10. رتب الأجهزة التي تدربت عليها حسب سهولتها بالنسبة لقاباليتك في أدائها

\begin{tabular}{|c|c|c|c|c|c|c|c|c|c|c|}
\hline \multicolumn{2}{|c|}{ المتواني } & \multicolumn{2}{|c|}{ المقابض } & \multicolumn{2}{|c|}{ حصان القزز } & \multicolumn{2}{|c|}{ الارضركاث } & \multicolumn{2}{|c|}{ العقلة } & \multirow[t]{2}{*}{ الاجابة } \\
\hline$\%$ & ك5 & $\%$ & ك & $\%$ & ك & $\%$ & ك & $\%$ & 5 & \\
\hline$\% \backslash \wedge$ & pr & $\% 11$ & $r$. & $\% \backslash V$ & rr & $\% 0$. & 9. & $\% 1 r$ & Y & 1 \\
\hline \% ro & r & $\% / r$ & $r$ & $\% 19$ & & $\% 19$ & & $\%$ ro & $\varepsilon 0$ & $r$ \\
\hline$\%$ rr & \&1 & $\% 17$ & $\mu$. & $\%$ \% & $\varepsilon \wedge$ & $\%$ \% & $\varepsilon \varepsilon$ & \%rr & $\varepsilon r$ & $r$ \\
\hline$\% 10$ & $r \wedge$ & $\% r$. & rq & $\%$ rr & $r q$ & $\% 1$. & 19 & \%ry & $\varepsilon V$ & $\varepsilon$ \\
\hline$\% 9$ & iv & $\% \varepsilon$. & Vr & $\% 17$ & 11 & $\% \wedge$ & $1 \leq$ & $\% 1 \varepsilon$ & ro & 0 \\
\hline$\% 1 \ldots$ & $|\wedge|$ & $\% 1 \ldots$ & $|\wedge|$ & $\% 1 \ldots$ & $|\wedge|$ & $\% 1 \ldots$ & $|\wedge|$ & $\% 1 \ldots$ & $|\wedge|$ & المجموع \\
\hline
\end{tabular}

\begin{tabular}{|c|c|c|c|c|c|}
\hline الخامستة المبة الت & الرابعة / المبة & الثالثة الثبة / ك & الثانية / المرتبة & الاولى / المرتبة & الجهاز \\
\hline $1 \varepsilon$ & 19 & $\varepsilon \varepsilon$ & ع & 9. & الحركات الارضية \\
\hline iv & $r \wedge$ & \& & rT & rr & المتوازي \\
\hline r^ & pq & $\varepsilon \wedge$ & ع & r & حصان الققز \\
\hline ro & $\varepsilon V$ & \& & $\leq 0$ & Y & العقلة \\
\hline Vr & و & r. & $r r$ & $r$. & حصان المقابض \\
\hline
\end{tabular}

تبين للباحثين ومن خلال الجدولين بأن ترتيب الأجهزة يكون كالتالي وحسب قابلية الطالب في أدائها

ا ـ المرتبة الأولى : الحركات الأرضية

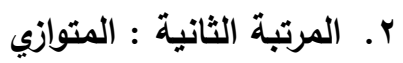
r. المرتبة الثالثة : عصان القفز

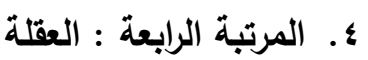

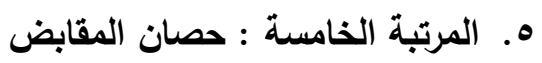

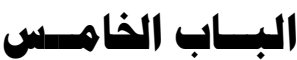

0- الاستـنتاجات والتوصيات 0-1اساستنتاجات

1. كفاية عدد الحصص التي يتلقاها الطالب في درس الجمناستك

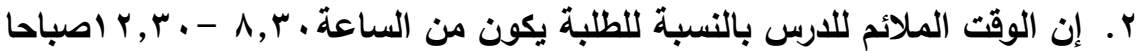
r. رغبة الطلبة في تعلم المهارات الخاصة بدرس الجمناستك لفك ؛. الطريقة المستخدمة من قبل المدرس لتصحيح الأخطاء تلقى قبولا هـ مشاركة المدرس في أداء الحركات جوانب ايجابية على نفسية الطالب 
7. هنالك أهمية كبيرة للاروس النظرية إذا مـا كان هنالك ترابط بينهاوبين الدروس العملية إضافة إلى

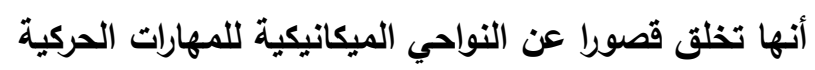

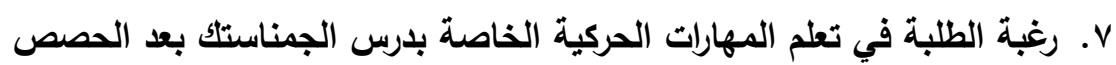

^. عرض الحركة من قبل المدرس تلقى قبولا إضافة إلى استخدام صور تحليلية وتوضيحية بلهية

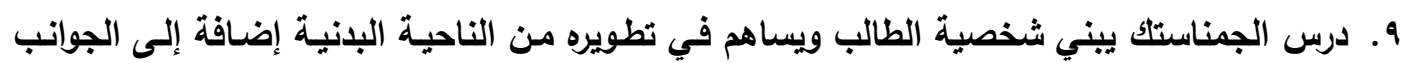

$$
\text { التربوية }
$$

ـ 1 ـ الحركات الأرضية هي أسـهل الحركات بالنسبة للأجهزة ويليها جهاز المتوازي،حصان القفز،العقلة

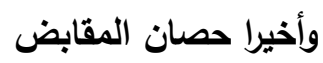

r-o

ا ـ ضرورة تحديد أوقات للتمرين على المهارات التي يلاقي الطالب فيها صعوية في الأداء لأجل الوصول

لأفضل صيغ العمل ومستوى نموذجي لتطبيق درس الجمناستك بأكمل وجه ألهات

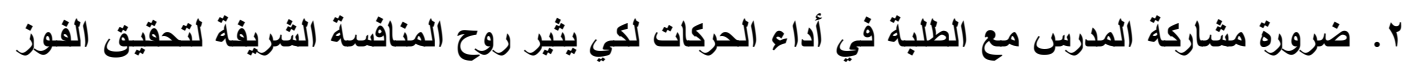

$$
\text { ومدى تأثير الجوانب النفسية على الطالب }
$$

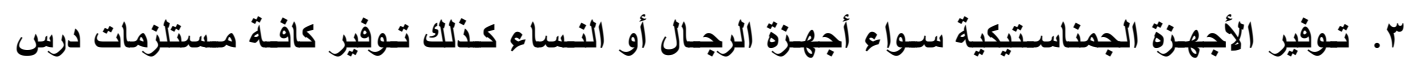
جمناستك الأجهزة بالنسبة للنساء والجمناستك الإيقاعي الحديث ويالمقاييس القانوني

ع. ضرورة زيادة عدد التدريسيين المتخصصين بالجمناستك الفني

$$
\text { ه. توفير الأفلام السينمائية }
$$

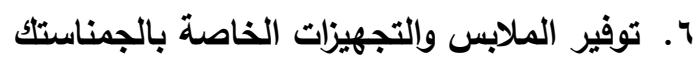

V. تعيين طبيب مختص بالإصابات الرياضية والطب الرياضي في الكلية

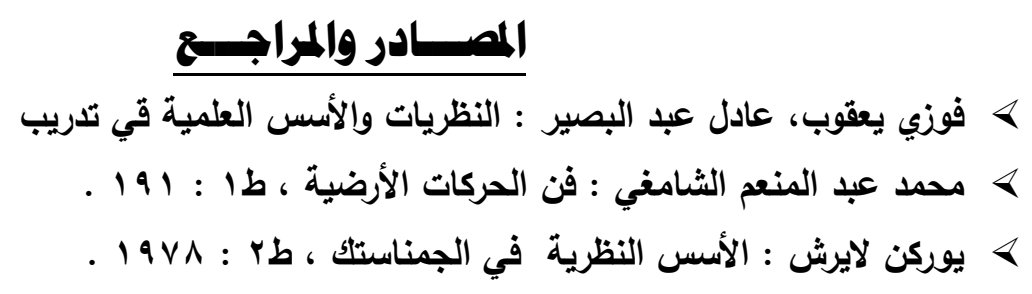

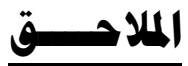

هلمق رقم (1)

استمهارة استبيان لتقييم درس البمناستك

عزيزي الطالب عزيزتي الطالبة :

بين يديك استمارة استبيان تتضمن بعض الاسئلة حول درس الجمناستك قومي الاستمارة للتعرف

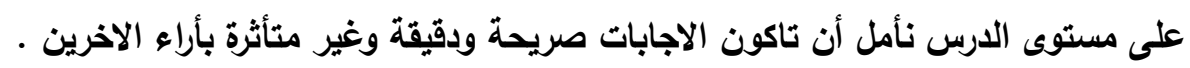

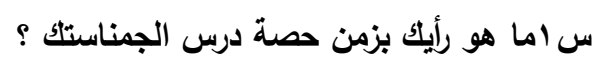

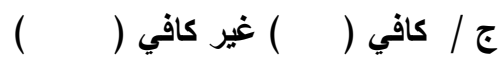
س r - ما هو الوقت المناسب لارس الجمناستك؟

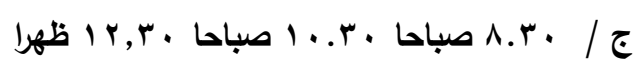




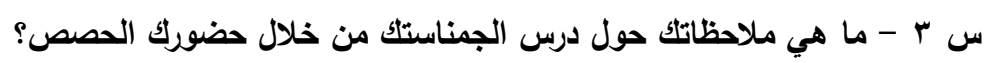

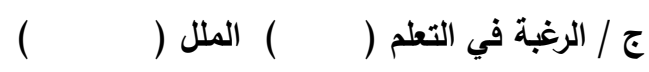

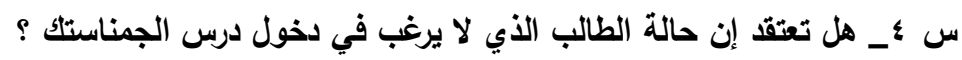

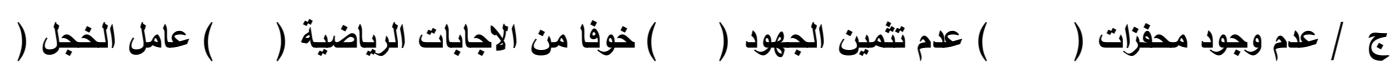

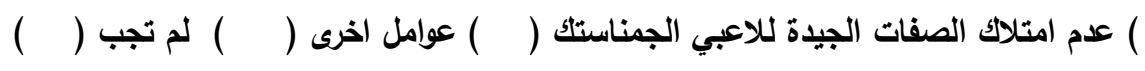

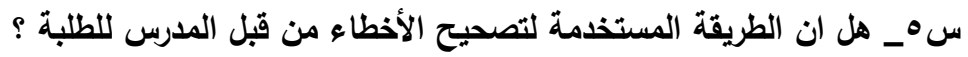

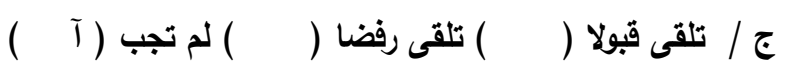

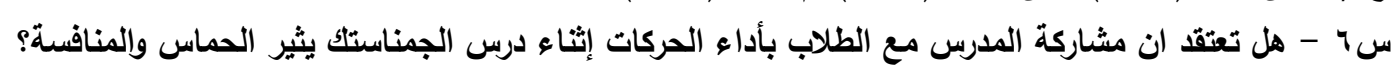

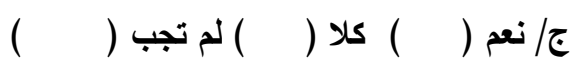
س V - ما هي أفضل طريقة بتصورك يستخدمها المدرس في عقوية|لمشاكسين والمشاغبين إثناء الحصة ؟

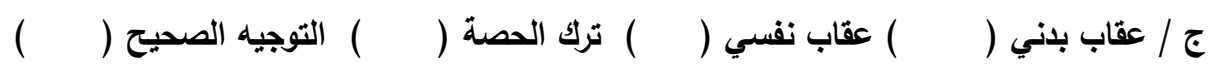

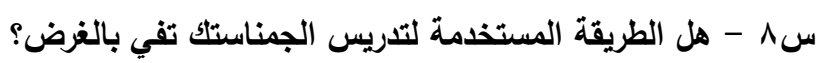

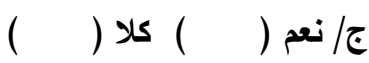

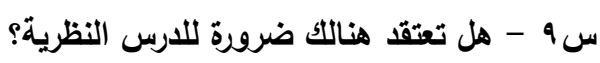

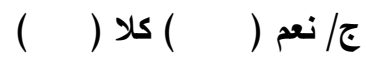

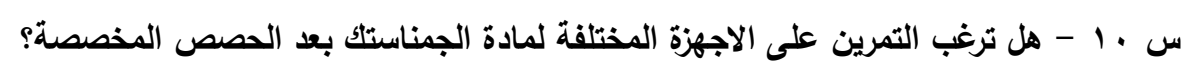

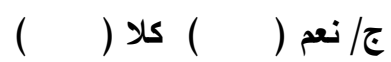
س 11 - هل تعتق إن الدروس النظرية تصور لايك النواحي الميكانيكية التي تحدث في أجزاء الحركة قبل ادأك لها؟

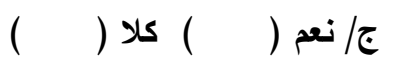

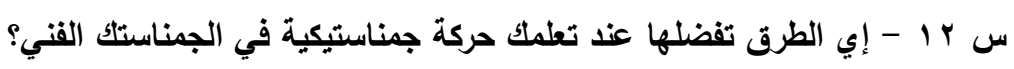

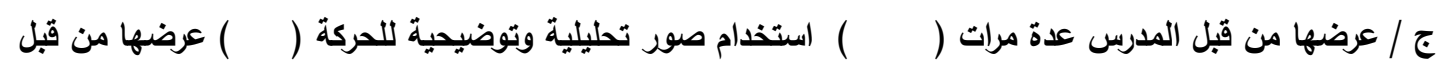

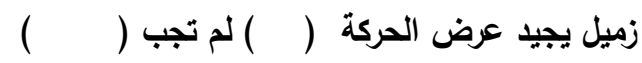

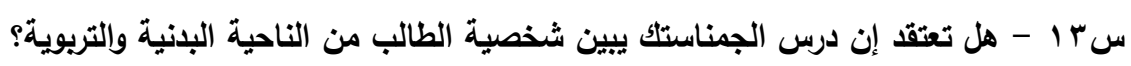

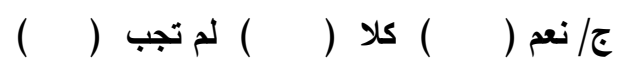
س ؛ 1 - هل هنالك مقترحات تود ذكرها تساعد على تطوير درس الجمناستك في الكلية ؟

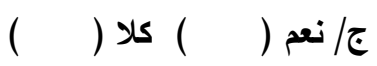
س 10 - رتب الأجهزة التي تدريت عليها حسب سهولتها بالنسبة لقابليتك في أدائها ؟

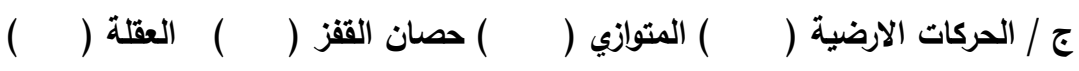
حصان المقابض ( ( ) ) 